\title{
Signal protein-functionalized gold nanoparticles for nuclear targeting into osteosarcoma cells for use in radiosensitization experiments
}

\author{
Z. BURES ${ }^{1,2, *}$, T. MAMO ${ }^{3}$, M. VLCEK ${ }^{4}$, L. LU $U^{5,6}$, M. J. YASZEMSKI ${ }^{5,6}$ \\ ${ }^{1} 3^{\text {rd }}$ Department of Internal Medicine, University Hospital and Faculty of Medicine in Hradec Kralove, Charles University, Hradec Kralove, \\ Czech Republic; ${ }^{2}$ Department of General and Inorganic Chemistry, Faculty of Chemical Technology, University of Pardubice, Pardubice, Czech \\ Republic; ${ }^{3}$ Department of Molecular Pharmacology and Experimental Therapeutics, Mayo Clinic Graduate School of Biomedical Sciences, \\ Mayo Clinic, Rochester, Minnesota, USA; ${ }^{4}$ Center of Materials and Nanotechnology, Faculty of Chemical Technology, University of Pardubice, \\ Pardubice, Czech Republic; ${ }^{5}$ Department of Orthopedic Surgery, Mayo Clinic School of Graduate Medical Education, Mayo Clinic, Rochester, \\ Minnesota, USA; ${ }^{6}$ Department of Physiology and Biomedical Engineering, Mayo Clinic Graduate School of Biomedical Sciences, Rochester, \\ Minnesota, USA
}

${ }^{*}$ Correspondence: $z$ denekburesmd@gmail.com

Received July 10, 2019 / Accepted September 29, 2019

\begin{abstract}
The standard therapy for malignant primary bone tumors such as osteosarcoma involves major surgeries. For tumors located in difficult regions such as the pelvis, surgical intervention could lead to serious side effects for example loss of a limb and/or function, loss of bowel, bladder and sexual function as well as problems with wound healing and surgical complications. Therefore, exploring other approaches that can improve or complement current surgical techniques is important. Hence, sensitizing primary bone tumors to radiation could offer an additional strategy that could complement surgery and significantly improve survival and quality of life. Gold nanoparticles (AuNPs) have been shown to enhance radiosensitivity by increasing the local dose of radiation inside tumors. Therefore, the referred procedure of preparation and functionalization of gold nanoparticles may be used for investigation whether DNA repair inhibition in the presence of AuNPs leads to an effective radiosensitizing strategy for primary bone tumor cells and explore the mechanism of how this may be happening. In our work, we prepared gold nanoparticles and verified the relation between the size of the AuNPs and their uptake in tumor 143B cells and also investigated whether the optimal size of the AuNPs should not be smaller than the size of nuclear envelope pores (20-50 nm). Hence, two different AuNPs systems were prepared: the first one with AuNPs core size of about $5 \mathrm{~nm}(\mathrm{BS})$ and the second one with AuNPs core size of about $50 \mathrm{~nm}$ (ZA). For cellular AuNPs uptake enhancement, we functionalized the AuNPs with signaling peptides. For this purpose we prepared PEG-coated AuNPs functionalized with signal peptides for targeted transport into the cytoplasm (CPP) and into the cell nucleus (CPP + NLS). The toxicity of the AuNPs systems was assessed by MTS assay. We prepared stable functionalized AuNPs systems of both sizes. With the functionalizing of the AuNPs using signal peptides (CPP, NLS), the AuNPs penetrated into the cell nucleus. The referred procedure of preparation and functionalization of gold nanoparticles may be used for investigating inhibition of DNA repair in the presence of AuNPs and it could lead to new understanding in overcoming radioresistance in primary bone tumor cells.
\end{abstract}

Key words: osteosarcoma, gold nanoparticles, cellular uptake, nuclear targeting, nanoparticles functionalization, radiosensitization

Gold nanoparticles (AuNPs) have been attracting increasing attention in the fields of drug and gene delivery, medical imaging, diagnosis and cancer treatment thanks to their efficiency in penetrating cells, and their ability to respond to light in near-infrared and high energy photons [1]. Gold nanomaterials have also attracted considerable interest as potential agents for photothermal therapy [2] and radiotherapy where they can be used as radiosensitizers [3]. AuNPs have been shown to sensitize cancer cells to kilovoltage radiation in vitro and in vivo [4]. Small size, biocompatibility, and passive accumulation of AuNPs in tumors make them attractive for use in cancer therapy. AuNPs have been shown to enhance the radiosensitivity by increasing the local dose of radiation inside tumors [5-10]. The increased local dose is attributed to the high atomic number of gold that leads to increased photon absorption and Auger electrons generation [11]. While most of the reports attribute the efficacy of AuNPs to the local radiation dose increase, recent reports 
are pointing towards additional biological mechanisms of action. Various investigators have shown that intracellular presence of AuNPs, without radiation, leads to elevated levels of reactive oxygen species (ROS) by inducing oxidative stress as well as causing mitochondrial and DNA damage [12]. These similar effects of oxidative stress, mitochondrial and DNA damage, could play a role in the radiosensitizing effects of AuNPs [13-15], but detailed mechanistic studies lack. Another essential question that remains to be fully elucidated is whether the intracellular location of AuNPs has a critical role in determining the radiosensitizing effects [13]. El-Sayed et al. have indicated that targeting AuNPs to the nucleus using a nuclear localizing signal (NLS) peptide causes DNA damage and leads to cell cycle arrest [16-17], but the effects of such nuclear targeting have not been investigated in the context of radiation. As the biological mechanisms of AuNPs radiosensitization continue to be elucidated, it could be very interesting to investigate the pharmacological inhibition of DNA repair in the presence of AuNPs for enhancing radiosensitization of primary bone tumors. In vivo, even in the absence of functionalization, nanoparticles passively accumulate at tumor sites that have leaky, immature vasculature with wider fenestrations than normal mature blood vessels. This is known as the enhanced permeability and retention (EPR) effect $[4,18]$. The size, shape, surface charge, and surface coating of nanoparticles all can modulate the uptake of nanoparticles into cells [19]. In the literature there was demonstrated that the cellular uptake of AuNPs was strongly size-dependent, $50 \mathrm{~nm}$ nanoparticles showing the highest uptake [20]. A surface charge can also have an effect on cellular uptake [21]. It has been shown that electropositive nanoparticles exhibited a higher efficiency of cellular uptake compared to electronegative nanoparticles, as assessed using monocyte-derived dendritic cells [22]. As it is typically observed, functionalization with PEG-thiols allows the AuNPs to be well dispersed in aqueous solution (sterical stabilization). PEG-thiols can effectively prevent the adhesion of plasma proteins and phagocytosis by the immune system by the formation of an outer polymer layer on the nanoparticle surface $[23,24]$. PEG layer on the AuNPs surface also prolongs their systemic blood circula- tion half-time via preventing them from being recognized by the reticulo-endothelial system organs (spleen, liver) [25]. The EPR effect combined with longer circulation times of AuNPs achieved by PEG-ylation, can increase concentrations of potential drugs in tumors by 10-100-fold compared with the use of free drugs [26]. The cell nucleus is a desirable target because the genetic information is situated there. Nuclear targeting of AuNPs in living cells has been generating a widespread interest because of the prospect of developing novel therapeutic strategies. Nuclear delivery of the nanoparticles requires bypassing the cellular membrane and the nuclear membrane. Unfunctionalized nanoparticles mostly localize only into the cytoplasm. One approach to targeted nuclear delivery is the conjugation of AuNPs to cell penetrating peptides (CPPs) and nuclear localization signal (NLS) - nuclear-penetrating peptide. CPPs are short cationic peptide sequences that have been demonstrated to mediate the intracellular delivery of a range of biological cargos. They were identified while investigating the ability of the HIV TAT transactivation protein to penetrate cells and activate HIV-1specific genes [27]. NLS was first discovered during the analysis of mutants of SV40 virus that produced an abnormal form of the early viral protein called large T-antigen (the wild-type form of this protein is localized in the nucleus in virus-infected cells, whereas mutated forms of large T-antigen accumulate in the cytosol). The mutations responsible for this altered cellular localization all occur within five consecutive basic amino acids in the sequence Pro-Lys-LysLys-Arg-Lys-Val. Moreover, 5-nm gold particles coated with this synthetic peptide are transported through nuclear pores after microinjection into the cytoplasm of cultured cells. These experiments demonstrated that this short sequence from SV40 large T-antigen acts as a signal that causes the targeted transport into the nucleus [28].

For this purpose, we synthesized AuNPs with a core size of $5 \mathrm{~nm}$ and $50 \mathrm{~nm}$, to compare whether the smaller particles would be better since the nuclear pore size is around 20-50 nm. For the synthesis, different reducing agents were used to obtain the required sizes. Prepared nanoparticles were stabilized with PEG (mPEG-thiol) to prevent aggregation before adding the targeting peptides. In addition to
A

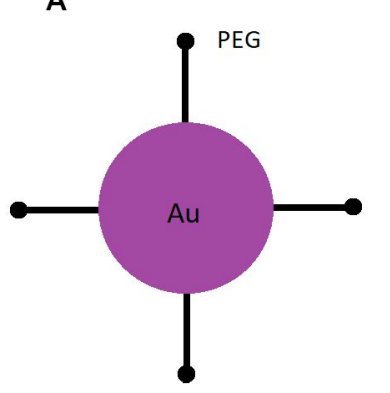

B

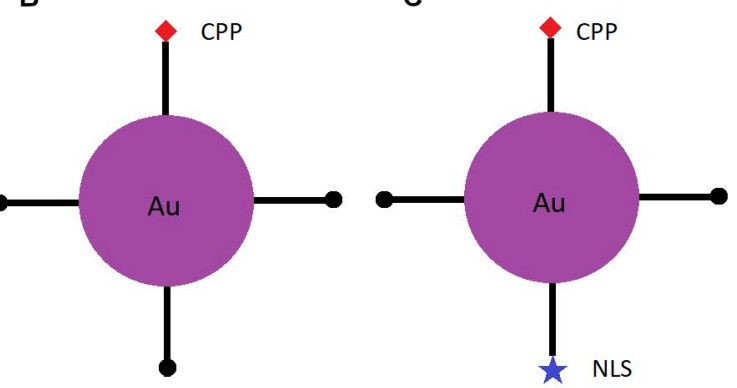

Figure 1. Types of different AuNPs. A) AuNPs with PEG; B) AuNPs with PEG and CPP for cytoplasmic targeting; C) AuNPs with PEG, CPP, and NLS for nuclear targeting. 
nuclear targeting, we functionalized AuNPs by cytoplasmic targeting peptide for an efficient uptake into osteosarcoma $143 \mathrm{~B}$ cells and also as a control of the nuclear targeting aspect. We used the NLS peptide sequence CGGGPKKKRKVGG and cytoplasmic targeting peptide sequence RGDRGDRGDRGDPGC, utilized the terminal cysteine group of peptides to conjugate to the surface of AuNPs. Our experimental plan for the types of AuNPs is shown in Figure 1.

\section{Materials and methods}

Materials. Tetrachloroauric acid trihydrate, ascorbic acid, sodium borohydride, sodium citrate, dimethyl sulfoxide - in analytical grade, Dulbecco's Modified Eagle's Medium and Dulbecco's Phosphate-Buffered Saline (PBS) were purchased from Sigma-Aldrich, St. Louis, Missouri. Methoxy-polyethyleneglycol-thiol (MW $5000 \mathrm{~g} / \mathrm{mol}$, mPEG-SH), was purchased from Laysan Bio, Inc. Trump's fixative (1\% glutaraldehyde and $4 \%$ formaldehyde in $0.1 \mathrm{M}$ phosphate buffer, $\mathrm{pH}$ 7.2) was obtained from Electron Microscopy Sciences, Hatfield, Pennsylvania, USA. CellTiter $96^{\circledR}$ AQueous One Solution Cell Proliferation Assay kit was obtained from Promega, Madison, WI, USA. Distilled water was further purified using a Milli-Q reagent grade water system (Millipore) to obtain Millipore water. Purified and lyophilized peptides were obtained from the Mayo Protein Core Facility.

Preparation of gold nanoparticles. The reduction of tetrachloroaurate ions by different types of reducing agents is a very often-used method for gold nanoparticles synthesis. Gold nanoparticles were synthesized by the reduction of tetrachloroauric acid with ascorbic acid and sodium borohydride with the presence of sodium citrate.

BS AuNPs ( $\sim 5 \mathrm{~nm}$ core size) synthesis. For the synthesis, a mixture of $50 \mathrm{ml}$ of $0.5 \mathrm{mM}$ tetrachloroauric acid solution with $50 \mathrm{ml}$ of $0.5 \mathrm{mM}$ sodium citrate solution was put in the conical flask $(250 \mathrm{ml})$. To this mixture we quickly added $5 \mathrm{ml}$ of freshly prepared solution of $0.1 \mathrm{M}$ sodium borohydride under the vigorous stirring.

ZA AuNPs ( $~ 50 \mathrm{~nm}$ core size $)$ synthesis. Into the mixture of $25 \mathrm{ml}$ of $1 \mathrm{mM}$ tetrachloroauric acid solution and $50 \mathrm{ml}$ of Millipore water in a conical flask $(250 \mathrm{ml}), 25 \mathrm{ml}$ of freshly prepared $0.06 \%$ L-ascorbic acid solution were added under the vigorous stirring.

Stabilization of AuNPs - PEG-ylation. Nanoparticles, since they have large surface areas, can easily agglomerate to form either small clusters or larger particles to minimize the total surface or interfacial energy of the whole system, then it is necessary to ensure repulsive interparticle forces to prevent the agglomeration of these particles. Prepared aqueous solutions of gold nanoparticles were then stabilized by PEG-ylation, which is necessary to prevent the aggregation of nanoparticles. At the first step, we measured the hydrodynamic diameter of both aqueous solutions of prepared nanoparticles (ZA, BS) by DLS (Dynamic Light Scattering) to ensure there will be space on the surface of nanoparticles for conjugation with targeting peptides. DLS spectra were carried out in a Zetasizer Nano, Malvern.

Conjugation of AuNPs with targeting peptides. The molar concentrations (C) of the prepared AuNPs solutions were calculated by dividing the total number of gold atoms $\left(\mathrm{N}_{\text {Total }}\right.$, equivalent to the initial amount of gold salt added to the reaction solution) over the average number of gold atoms per nanosphere $(\mathrm{N})$ as $\mathrm{C}=\mathrm{N}_{\text {Total }} / \mathrm{NVN}_{\mathrm{A}}$, where $\mathrm{V}$ is the volume of the reaction solution in liter and $\mathrm{N}_{\mathrm{A}}$ is the Avogadro's constant. It is assumed that the reduction from gold(III) to gold atoms was $100 \%$ complete [29]. Gold nanoparticles were concentrated by centrifugation at $13400 \times \mathrm{g}$ for $30 \mathrm{~min}$. The supernatant was removed and nanoparticles were placed under UV lamp for $20 \mathrm{~min}$ in the laminar flow box. After those nanoparticles were redispergated into sterile PBS to reach concentration $0.4 \mathrm{mM}$ and then calculated amounts of CPP (RGDRGDRGDRGDPGC, MW $1587 \mathrm{~g} / \mathrm{mol}$ ) or CPP and NLS (CGGGPKKKRKVGG, MW $1270 \mathrm{~g} / \mathrm{mol}$ ) solutions were added to reach the concentration 10000 times more than AuNPs (0.4 mM) concentration (for CPP), and 100000 times higher than AuNPs concentration (for NLS). The solutions were stirred for 24 hours.

In vitro cytotoxicity assay. Cell viability of $143 \mathrm{~B}$ cells was determined using the MTS assay - CellTiter $96^{\bullet}$ AQueous One Solution Cell Proliferation Assay. The assay was carried out in sterile 96 well flat bottom microplates. $100 \mu$ of media at $10^{5}$ cells $/ \mathrm{ml}$ was seeded in each well of the 96 well plate and the plate was incubated at $37^{\circ} \mathrm{C}$ in a $5 \% \mathrm{CO}_{2}$ humidified incubator for $24 \mathrm{~h}$. After $24 \mathrm{~h}$ the cell monolayer was washed with sterile PBS and then incubated with $100 \mu \mathrm{l}$ AuNPs conjugates ( $0.4 \mathrm{mM} \mathrm{ZA,} 0.4 \mathrm{mM} \mathrm{BS}$ ) in the complete cell culture medium, whereas $100 \mu \mathrm{l}$ of $10 \%$ (v/v) DMSO (dimethyl sulfoxide) in complete cell culture medium was used as a positive control for all the cell lines. After $24 \mathrm{~h}$ exposure, the medium was removed and the cell monolayer was washed with sterile PBS. After washing, $100 \mu \mathrm{l}$ of MTS reagent solution 1:6 (v/v) diluted in cell culture medium was added to each well. After the addition of MTS reagent, the 96 well plate was incubated at $37^{\circ} \mathrm{C}$ in a $5 \% \mathrm{CO}_{2}$ humidified incubator for $1 \mathrm{~h}$ and then the absorbance was measured at $490 \mathrm{~nm}$ using a microplate reader. Three independent experiments were performed for each AuNPs formulation. The percentage of cell viability was calculated as compared to untreated cells. Data are presented as mean \pm standard deviation $(n=3)$. All the AuNPs were sterilized under the UV lamp in the laminar flow box for 20 min prior to performing cell viability experiments.

Cell culture and particle delivery. Osteosarcoma cell line 143B was obtained from Mayo Clinic, Rochester, MN. 143B cells were cultured in Dulbecco's Modified Eagle's medium (DMEM) with $1 \%(\mathrm{v} / \mathrm{v})$ antibiotics (streptomycin $10000 \mu \mathrm{g} / \mathrm{ml}$, penicillin $10000 \mathrm{IU} / \mathrm{ml}$ ) and $10 \%$ (wt/v) fetal bovine serum at $37^{\circ} \mathrm{C}$ in a humidified atmosphere containing $5 \% \mathrm{CO}_{2}$. For investigating the cellular localization of gold nanoparticles, cells were plated in 6 well plates and grown 
to $75-80 \%$ confluency and then incubated with nanoparticle conjugates for 24 hours with serum containing media.

Transmission electron microscopy. Cell samples were washed with PBS and fixed in Trump's fixative. Osteosarcoma cells were then rinsed for $30 \mathrm{~min}$ in 3 changes of $0.1 \mathrm{M}$ phosphate buffer, $\mathrm{pH} 7.2$, followed by a one-hour postfix in phosphate-buffered 1\% osmium tetroxide. After rinsing in 3 changes of distilled water for 30 min the tissue was en bloc stained with $2 \%$ uranyl acetate for $30 \mathrm{~min}$ at $60^{\circ} \mathrm{C}$. After en bloc staining, the tissue was rinsed in three changes of distilled water, dehydrated in progressive concentrations of ethanol and 100\% propylene oxide and embedded in Spurr's resin. Thin sections were cut on a Reichert Ultracut E ultramicrotome, placed on 200 mesh copper grids and stained with lead citrate. TEM analysis was carried out in a JEOL JEM-1400 TEM electron microscope working at $80 \mathrm{kV}$.

Functionalized nanoparticles cellular uptake. Evaluation of Cellular Uptake of AuNPs. 143B cells were plated in 6 well plates at a density of $5.0 \times 10^{4}$ cells/well. After $24 \mathrm{~h}$ growth the medium was removed and a fresh medium containing $0.4 \mathrm{nM}$ of functionalized AuNPs $(2 \mathrm{ml})$ was added. $143 \mathrm{~B}$ cells were incubated for 24 hours at $37^{\circ} \mathrm{C}$. Finally, the cells were washed twice with PBS, fixed, and sectioned. Each section was placed onto a copper grid and imaged by TEM.

\section{Results and discussion}

For assessing the AuNPs transport into osteosarcoma $143 \mathrm{~B}$ cells and subsequent evaluation of their ability to penetrate the nuclear envelope, AuNPs with a core size of $5 \mathrm{~nm}$ and $50 \mathrm{~nm}$ were tested.

Before cell culture experiments it was necessary to prepare nanoparticles of desired core sizes. For this purpose, an original method of synthesis was developed. All syntheses used tetrachloroauric acid as a source of auric ions, which were further reduced using different reducing agents. For the preparation of BS AuNPs of smaller core size ( $5 \mathrm{~nm}$ ), sodium borohydride was used as a strong reducing agent. Sodium citrate works as a stabilizer there. To prepare ZA AuNPs of bigger core size $(50 \mathrm{~nm})$, ascorbic acid was used as a reducing agent. Ascorbic acid is, as well as sodium citrate, very suitable since it is not toxic.

The size of prepared nanoparticles was measured by DLS (Dynamic Light Scattering) performed on Zetasizer Nano (Figures 2A, 2B). Distribution curves show one peak with a narrow standard deviation. The hydrodynamic diameter $\left(D_{h}\right)$ of AuNPs (BS AuNPs $D_{\mathrm{h}}=12.8 \mathrm{~nm}, \mathrm{ZA} \mathrm{AuNPs} \mathrm{D}_{\mathrm{h}}=54.1 \mathrm{~nm}$ ) does not correspond completely to the core size because of the presence of electric double-layer on the nanoparticle surface. The core size of prepared nanoparticles was confirmed by using TEM. TEM images of the AuNPs systems show nearly uniform spherical nanoparticles with the core size about 5.4-5.8 nm (BS) with a nearly uniform particle size distribution (Figure 2C), spherical AuNPs (ZA) with the core size of about $17-53 \mathrm{~nm}$, the main fraction with size about $50 \mathrm{~nm}$. TEM image shows also the presence of nanorods (Figure 2D). UV-VIS spectra were carried out on Beckman DU-600 spectrophotometer, surface plasmon resonance peak for BS AuNPs with an average core size $5 \mathrm{~nm}$ is centered at $535 \mathrm{~nm}$ (Figure 2E). ZA AuNPs absorb at $529 \mathrm{~nm}$ wavelength of light (Figure 2F). Before the planned AuNPs functionalization with signaling peptides, we verified the relation between the hydrodynamic diameter and the amount of used PEG-SH (using DLS) in order to leave a free surface for binding the signaling peptides onto the AuNPs (Figure 3).

Before treating of AuNPs with signaling peptides, $10 \mu \mathrm{l}$ of $1 \mathrm{mM}$ PEG-SH (MW $5000 \mathrm{~g} / \mathrm{mol}$ ) and $490 \mu \mathrm{l}$ Millipore water per each $10 \mathrm{ml}$ of freshly prepared gold nanoparticles solution were used. Surface modification with PEG-SH causes red shift of UV-VIS spectra due to the change in the dielectric constant of the surrounding environment of AuNPs (Table 1).

The toxicity of the AuNPs conjugates was assessed by the MTS assay. MTS assay reported no significant decrease in $143 \mathrm{~B}$ cell viability when assessed with BS and ZA functionalized AuNPs (with CPP and CPP/NLS respectively) (Figure 4).

Viability of 143B cells incubated with ZA AuNPs functionalized by both CPP and CPP/NLS was increased ( 150\%) as well as the viability of $143 \mathrm{~B}$ cells incubated with BS AuNPs functionalized by both CPP and CPP/NLS was increased

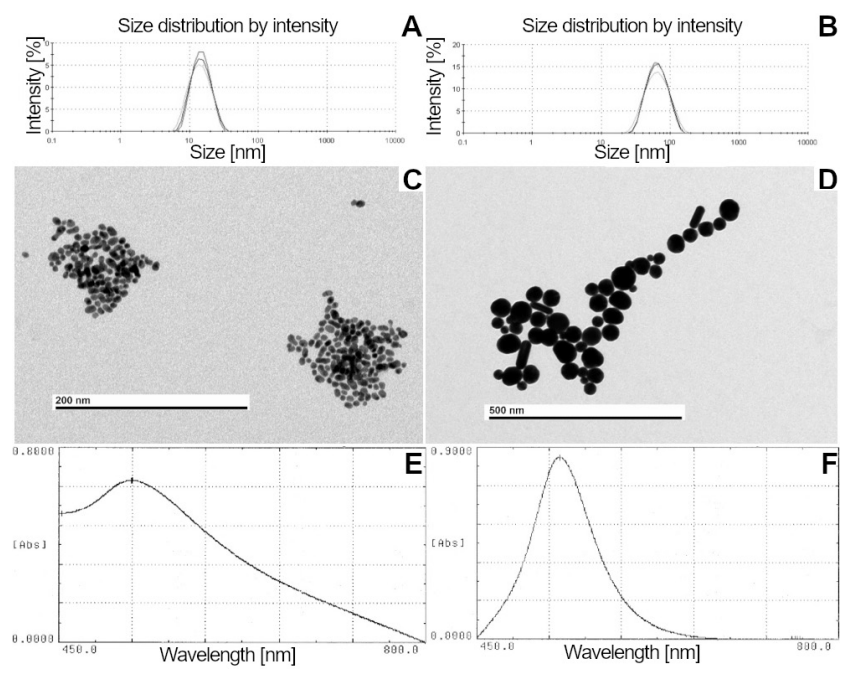

Figure 2. DLS curves of BS AuNPs (A) and ZA AuNPs (B), TEM micrographs of BS AuNPs (C) and ZA AuNPs (D), UV-VIS spectra of BS AuNPs (E) and ZA AuNPs (F).

Table 1. $\lambda_{\max }-$ maximum absorbance of AuNPs.

\begin{tabular}{lccc}
\hline Sample & PEG-SH $[\mathbf{1 m M}]$ & $\boldsymbol{\lambda}_{\max }[\mathbf{n m}]$ & $\mathbf{A}_{\max }$ \\
\hline BS & 0 & 520 & 0.6649 \\
BS & $10 \mu \mathrm{l}$ & 530 & 0.1911 \\
ZA & 0 & 529 & 0.8543 \\
ZA & $10 \mu \mathrm{l}$ & 530.5 & 0.8526 \\
\hline
\end{tabular}




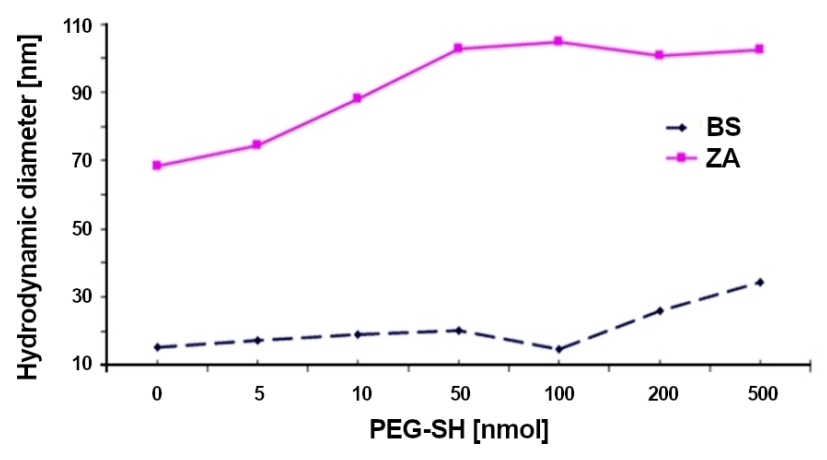

Figure 3. The relation between the hydrodynamic diameter of AuNPs and the amount of added PEG-SH.

(125-130\%). This effect was already observed by several authors, but its nature has not been clarified yet [30,31].

Employing osteosarcoma tumor cell lines 143B we verified the cellular uptake of non-functionalized AuNPs. TEM shows that the spontaneous cellular AuNPs uptake seems to be higher in $50 \mathrm{~nm}$-sized non-functionalized AuNPs than in $5 \mathrm{~nm}$-sized non-functionalized AuNPs (Figure 5). For cellular AuNPs uptake enhancement, we functionalized both systems of AuNPs with signaling peptides. For this purpose we prepared PEG-coated AuNPs functionalized with signal peptides for targeted transport into the cytoplasm (CPP) and into the cell nucleus (CPP/NLS). Peptide-functionalized AuNPs were subsequently tested in vitro with osteosarcoma cell line by transmission electron microscopy to determine the ability to cross the membranes. Both systems of AuNPs functionalized with signaling peptides are present in

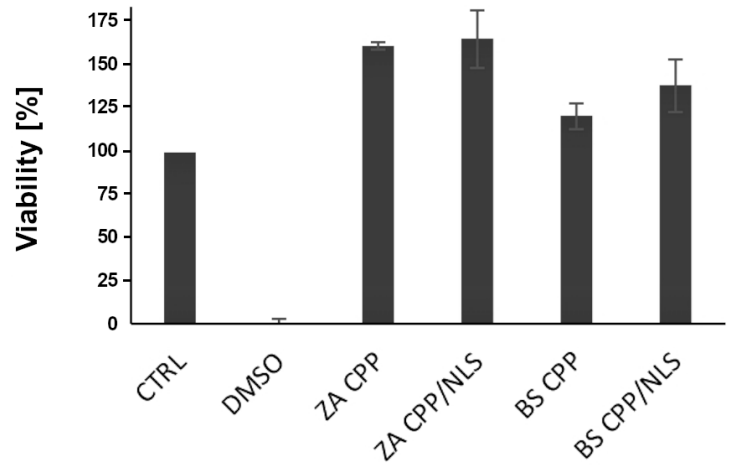

Figure 4. Assessment of the cell viability in 143B osteosarcoma cells after $24 \mathrm{~h}$ of nanoparticle exposure.

cytoplasm on TEM (Figure 6, Figure 7) when functionalized with CPP and in cell nuclei when functionalized with both CPP and NLS (Figure 7).

It seems that the highest cellular AuNPs uptake is shown in AuNPs with a core size of $50 \mathrm{~nm}$. Cellular AuNPs uptake can be enhanced with their functionalization using CPP. Nanoparticles functionalized by both CPP and NLS are able to penetrate into the cell nucleus. In cell nuclei, AuNPs of a core size of $50 \mathrm{~nm}$ can be seen on TEM.

We prepared two AuNPs systems, which would preserve their features for targeted transport into cells and cell nuclei, respectively. Therefore, the referred procedure offers a simple way how to synthesize AuNPs with the required size. These AuNPs are stable in their solutions after preparation for more than 3 months. Dispersions of AuNPs in PBS and cell culture media do not aggregate during the following experi-

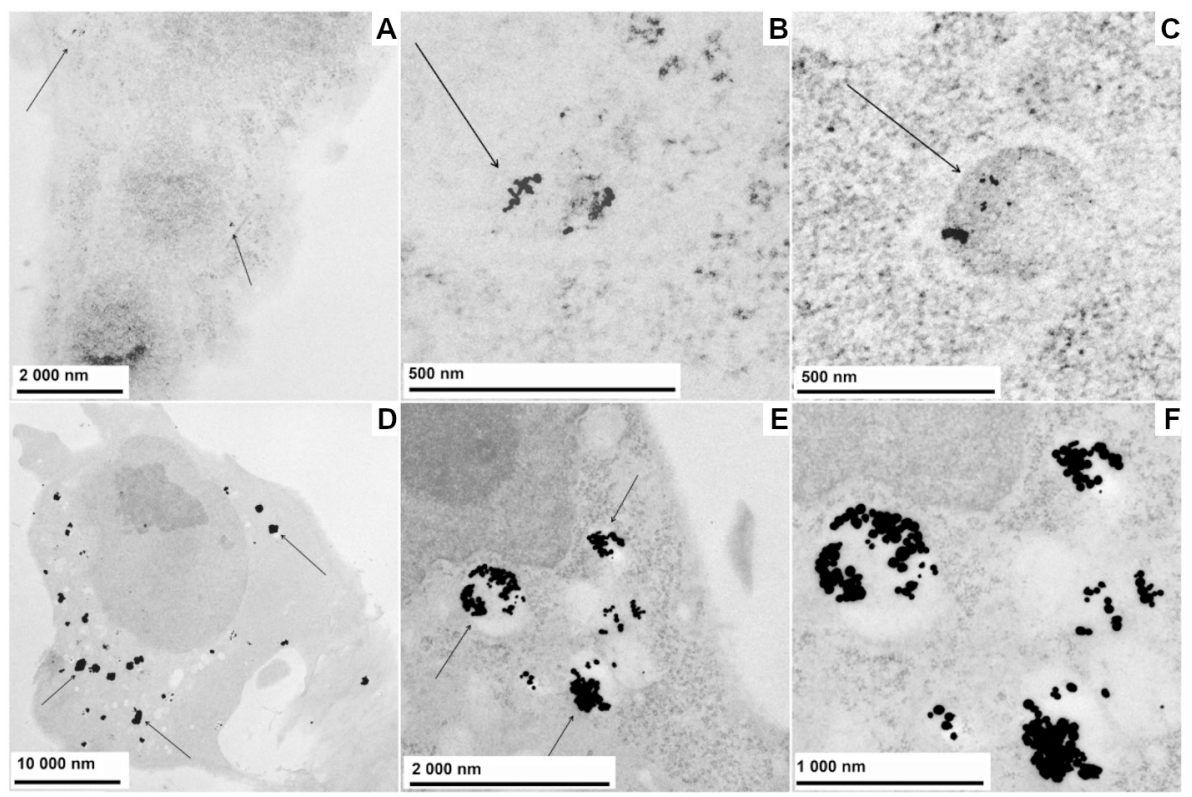

Figure 5. TEM micrographs of 143B cells incubated with unfunctionalized PEG-ylated BS AuNPs (A-C) and ZA AuNPs (D-F) for 24 hours at different magnifications. 


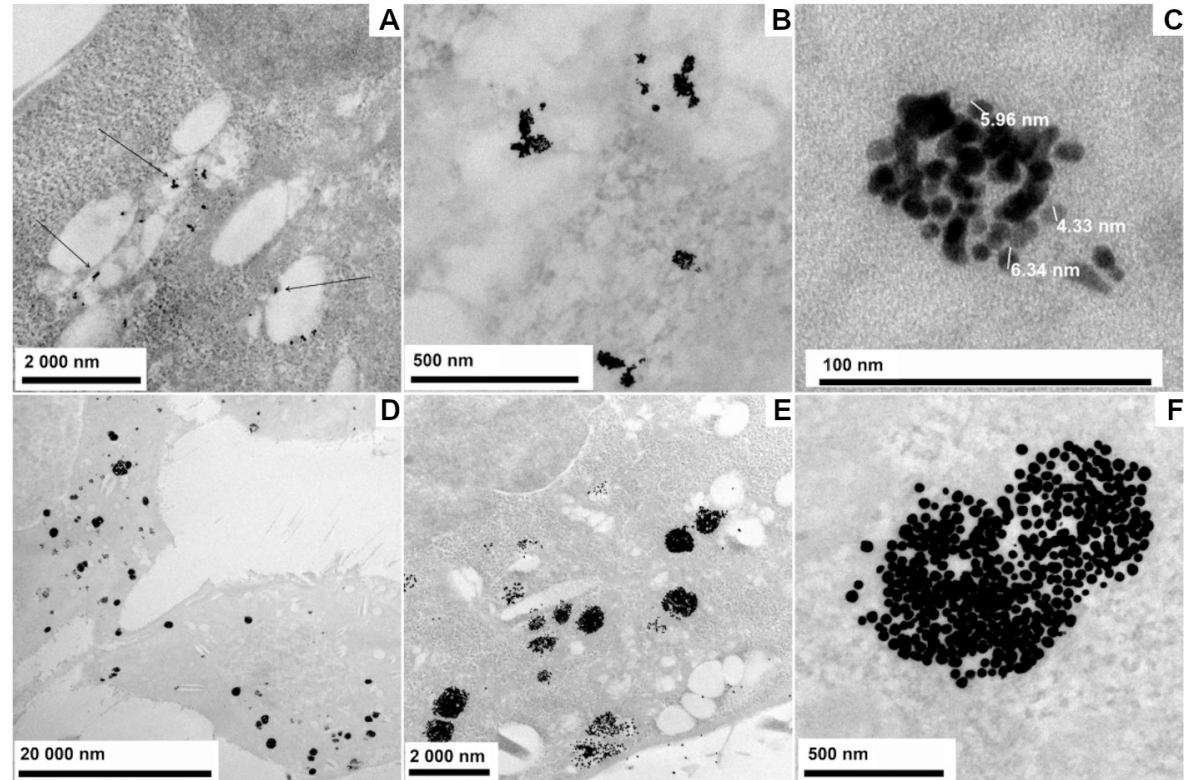

Figure 6. TEM micrographs of 143B cells incubated with CPP- functionalized PEG-ylated BS AuNPs (A-C) and ZA AuNPs (D-F) for 24 hours at different magnifications.

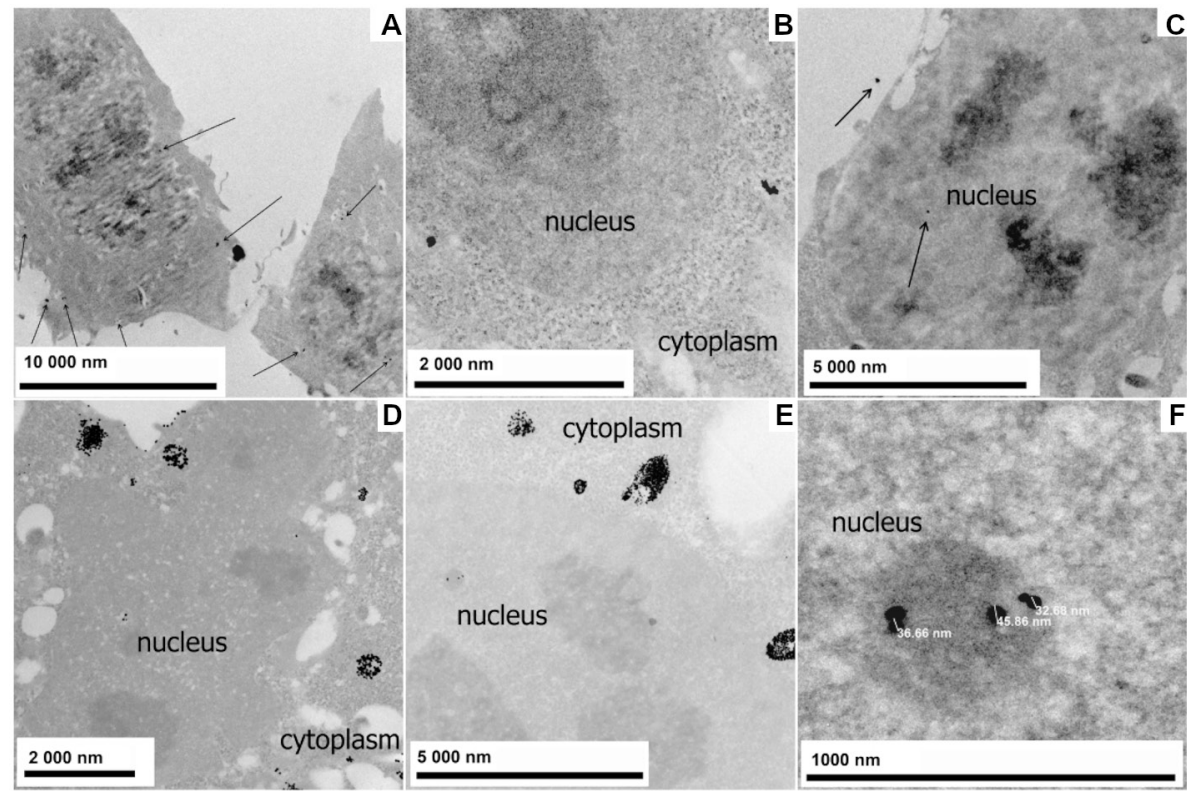

Figure 7. TEM micrographs of 143B cells incubated with CPP/NLS-functionalized PEG-ylated BS AuNPs (A-C) and ZA AuNPs (D-F) for 24 hours at different magnifications.

ments with 143B cell line. These AuNPs show a low acute in vitro cell toxicity. Thus, this method may be used in targeted drug delivery into tumor cells, for tumor cell radiosensitization respectively, where the nuclear AuNPs uptake may induce a higher irradiation response. The best results can be seen in ZA AuNPs with a core size of $50 \mathrm{~nm}$ where the spontaneous cellular uptake appears to be the highest and is enhanced by CPP functionalization. CPP bind to surface integrins, which are highly expressed on the surface of the cancer cells to enhance the receptor-mediated endocytosis of the nanoparticles selectively to the cancer cells. With their further functionalization using NLS, the ZA AuNPs are observed around the nuclear membrane and are recognized by importin and translocated into the cell nucleus. These nanoparticles are able to penetrate the nuclear envelope and reach the nucleoplasm. As the biological mechanisms of AuNPs radiosensitization continue to be elucidated, it will be very interesting to investigate the effect of AuNPs 
for enhancing the radiosensitivity of primary bone tumors. AuNPs for radiosensitizing primary bone tumors might shed light on understanding ways to overcome radioresistance.

\section{References}

[1] JAIN S, HIRST DG, O'SULLIVAN JM. Gold nanoparticles as novel agents for cancer therapy. Br J Radiol 2012; 85: 101113. https://doi.org/10.1259/bjr/59448833

[2] GARCIA CALAVIA P, BRUCE G, PEREZ-GARCIA L, RUSSEL DA. Photosensitiser-gold nanoparticle conjugates for photodynamic therapy of cancer. Photochem Photobiol Sci 2018; 17: 1534-1552. https://doi.org/10.1039/c8pp00271a

[3] SHRESTHA S, COOPER LN, ANDREEV OA, RESHETNYAK YK, ANTOSH MP. Gold Nanoparticles for Radiation Enhancement in Vivo. Jacobs J Radiat Oncol 2016; 3: 026.

[4] JAIN S, COULTER JA, HOUNSELL AR, BUTTERWORTH KT, MCMAHON SJ et al. Cell-specific radiosensitization by gold nanoparticles at megavoltage radiation energies. Int J Radiat Oncol Biol Phys 2011; 79: 531-539. https://doi. org/10.1016/j.ijrobp.2010.08.044

[5] KWATRA D, VENUGOPAL A, ANANT S. Nanoparticles in radiation therapy: a summary of various approaches to enhance radiosensitization in cancer. Transl Cancer Res 2013; 2: 330-342. https://doi.org/10.3978/j.issn.2218676X.2013.08.06

[6] POTTIER A, BORGHI E, LEVY L. New use of metals as nanosized radioenhancers. Anticancer Res 2014; 34: 443453.

[7] HAINFELD JF, DILMANIAN FA, ZHONG Z, SLATKIN DN, KALEF-EZRA JA et al. Gold nanoparticles enhance the radiation therapy of a murine squamous cell carcinoma. Phys Med Biol 2010; 55: 3045-3059. https://doi.org/10.1088/00319155/55/11/004

[8] JOH DY, SUN L, STANGL M, AL ZAKI A, MURTY S et al. Selective targeting of brain tumors with gold nanoparticle-induced radiosensitization. PLoS One 2013; 8: e62425. https://doi.org/10.1371/journal.pone.0062425

[9] MILADI I, ALRIC C, DUFORT S, MOWAT P, DUTOUR $A$ et al. The in vivo radiosensitizing effect of gold nanoparticles based MRI contrast agents. Small 2014; 10: 1116-1124. https://doi.org/10.1002/smll.201470036

[10] ARVIZO RR, BHATTACHARYYA S, KUDGUS RA, GIRI $\mathrm{K}$, BHATTACHARYA R et al. Intrinsic therapeutic applications of noble metal nanoparticles: past, present and future. Chem Soc Rev 2012; 41: 2943-2970. https://doi.org/10.1039/ c2 cs15355f

[11] MESBAHI A. A review on gold nanoparticles radiosensitization effect in radiation therapy of cancer. Rep Pract Oncol Radiother 2010; 15: 176-180. https://doi.org/10.1016/j. rpor.2010.09.001

[12] BUTTERWORTH KT, MCMAHON SJ, TAGGART LE, PRISE KM. Radiosensitization by gold nanoparticles: effective at megavoltage energies and potential role of oxidative stress. Transl Cancer Res 2013; 2: 269-279. https://doi. org/10.3978/j.issn.2218-676X.2013.08.03
[13] JEREMIC B, AGUERRI AR, FILIPOVIC N. Radiosensitization by gold nanoparticles. Clin Transl Oncol 2013; 15: 593601. https://doi.org/10.1007/s12094-013-1003-7

[14] SU XY, LIU PD, WU H, GU N. Enhancement of radiosensitization by metal-based nanoparticles in cancer radiation therapy. Cancer Biol Med 2014; 11: 86-91. https://doi. org/10.7497/j.issn.2095-3941.2014.02.003

[15] YASUI H, TAKEUCHI R, NAGANE M, MEIKE S, NAKAMURA $Y$ et al. Radiosensitization of tumor cells through endoplasmic reticulum stress induced by PEGylated nanogel containing gold nanoparticles. Cancer Lett 2014; 347: 151158. https://doi.org/10.1016/j.canlet.2014.02.005

[16] KANG B, MACKEY MA, EL-SAYED MA. Nuclear targeting of gold nanoparticles in cancer cells induces DNA damage, causing cytokinesis arrest and apoptosis. J Am Chem Soc 2010; 132: 1517-1519. https://doi.org/10.1021/ja9102698

[17] MACKEY MA, EL-SAYED MA. Chemosensitization of cancer cells via gold nanoparticle-induced cell cycle regulation. Photochem Photobiol 2014; 90: 306-312. https://doi. org/10.1111/php. 12226

[18] MAEDA $H$. The enhanced permeability and retention (EPR) effect in tumor vasculature: the key role of tumor-selective macromolecular drug targeting. Adv Enzyme Regul 2001; 41: 189-207. https://doi.org/10.1016/s0065-2571(00)00013-3

[19] XIE X, LIAO J, SHAO X, LI Q, LIN Y. The Effect of shape on Cellular Uptake of Gold Nanoparticles in the forms of Stars, Rods, and Triangles. Sci Rep 2017; 7: 3827. https://doi. org/10.1038/s41598-017-04229-z

[20] CHITHRANI BD, GHAZANI AA, CHAN WC. Determining the size and shape dependence of gold nanoparticle uptake into mammalian cells. Nano Lett 2006; 6: 662-668. https://doi.org/10.1021/nl052396o

[21] CHO EC, AU L, ZHANG Q, XIA Y. The effects of size, shape, and surface functional group of gold nanostructures on their adsorption and internalization by cells. Small 2010; 6: 517522. https://doi.org/10.1002/smll.200901622

[22] FYTIANOS K, RODRIGUEZ-LORENZO L, CLIFT MJ, BLANK F, VANHECKE D et al. Uptake efficiency of surface modified gold nanoparticles does not correlate with functional changes and cytokine secretion in human dendritic cells in vitro. Nanomedicine 2015; 11: 633-644. https://doi. org/10.1016/j.nano.2014.11.004

[23] MA ZY, XIA HX, LIU YP, LIU B, CHEN W et al. Applications of gold nanorods in biomedical imaging and related fields. Chin Sci Bull 2013; 58: 2530-2536. https://doi. org/10.1007/s11434-013-5720-7

[24] PERRAULT SD, WALKEY C, JENNINGS T, FISCHER HC, CHAN WC. Mediating tumor targeting efficiency of nanoparticles through design. Nano Lett 2009; 9: 1909-1915. https://doi.org/10.1021/nl900031y

[25] SINGH P, PANDIT S, MOKKAPATI VRSS, GARG A, RAVIKUMAR V et al. Gold Nanoparticles in Diagnostics and Therapeutics for Human Cancer. Int J Mol Sci 2018; 19: 1979. https://doi.org/10.3390/ijms19071979

[26] KAUL G, AMIJI M. Long-circulating poly(ethylene glycol)-modified gelatin nanoparticles for intracellular delivery. Pharm Res 2002; 19: 1061-1067. https://doi. org/10.1023/a:1016486910719 
[27] JONES SW, CHRISTISON R, BUNDELL K, VOYCE CJ, BROCKBANK SM et al. Characterisation of cell-penetrating peptide-mediated peptide delivery. Br J Pharmacol 2005; 145: 1093-1102. https://doi.org/10.1038/sj.bjp.0706279

[28] LODISH H, BERK A, ZIPURSKY SL, MATSUDAIRA P, BALTIMORE D et al (Eds.). Molecular Cell Biology. 4th edition. Section 11.4 Signal-Mediated Transport through Nuclear Pore Complexes. WH. Freeman, New York 2000. ISBN 0-7167-3136-3. Available from https://www.ncbi.nlm.nih. gov/books/NBK21649
[29] LIU X, ATWATER M, WANG J, HUO Q. Extinction coefficient of gold nanoparticles with different sizes and different capping ligands. Colloids Surf B Biointerfaces 2007; 58: 3-7. https://doi.org/10.1016/j.colsurfb.2006.08.005

[30] FALAGAN-LOTSCH P, GRZINCIC E M, MURPHY C J. One low-dose exposure of gold nanoparticles induces longterm changes in human cells. Proc Natl Acad Sci U S A 2016; 113: 13318-13323. https://doi.org/10.1073/pnas.1616400113

[31] XIAO Y, ZHANG E, FU A. Promotion of SH-SY5Y Cell Growth by Gold Nanoparticles Modified with 6-Mercaptopurine and a Neuron-Penetrating Peptide. Nanoscale Res Lett 2017; 12: 641. https://doi.org/10.1186/s11671-0172417-x 